Freiburg, Kiel and Frankfurt, have now also started going through their files to check for derecognition of doctorates and injustice in general in Nazi times.

Each university is proceeding in a different way, but all are checking every case individually. "We cannot and we do not grant a general rehabilitation," says Christian Winter, the vice-president of Frankfurt University.

"It is most important to discriminate between those who lost their titles on racial or political grounds and those who lost their titles on genuine criminal grounds."

Universities have found that it is not always easy to discriminate between the possibilities. Some cases are clear. For example, if the grounds for divestment of title were given simply as homosexuality or disloyalty to the Nazi regime, no longer crimes today, then rehabilitation would be automatic.

But if an academic was stripped of his or her title because of a financial offence, then the exact nature of the offence becomes important. Genuine criminal grounds were not unusual. Of 59 persons stripped of doctorates by Hamburg University, for example, eight were involved in genuine crime, including murder.

In the eastern part of Germany, some universities remain unaware of the issue - Rostock learned of its involvement only after being contacted by Nature. Other universities say they lack the resources to carry out time-consuming investigations.

For most of those affected, the efforts come far too late. Many have died, and it is difficult to track down those who are still alive. Aware of this, Munich University, in its 1996 statement reversing its own derecognition of 135 academic titles, described it as "first of all a gesture for the bereaved" with which the university "faces its responsibilities arising from its history". Matthiasstrobl

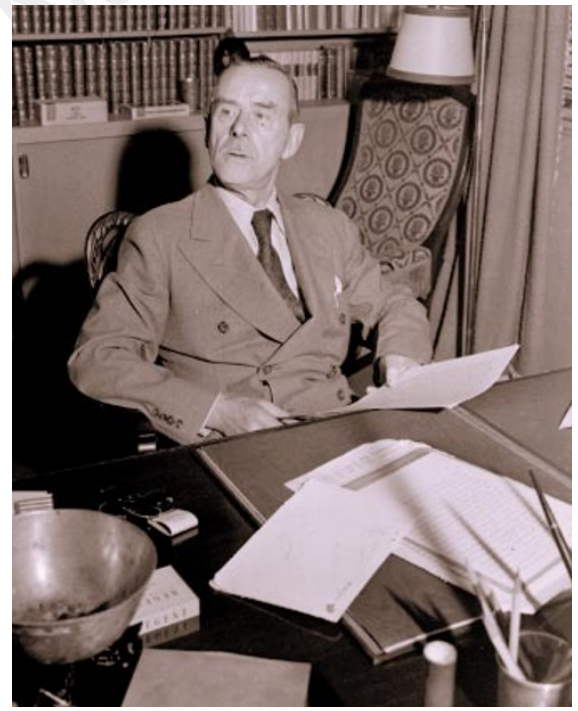

Honour regained: the author Thomas Mann was stripped of his honorary doctorate by the University of Bonn in 1936. It was returned to him on the university's initiative in $\mathbf{1 9 4 6 .}$

\title{
Nobel laureates in bid to revamp science teaching
}

[SAN FRANCISCO] A group that includes ten Nobel laureates will learn shortly whether it has been successful with its offer to restructure academic standards for California's science curriculum. The move follows a decision last month by a state commission to reopen a process under which the group's bid had earlier been rejected.

The Nobel prizewinners include such well-known names as David Baltimore, Glenn T. Seaborg, Henry Taube, Dudley Herschbach and Paul Berg, and the group is keen to counteract what its members regard as a 'dumbing down' trend in science education. It seeks to emphasize fundamental concepts and to ensure that schools produce competent students who will go on to science studies in colleges and universities.

The group says it would insist on wellwritten textbooks, scientifically trained teachers, better salaries for instructors, and a focus on basic scientific concepts and mechanisms. It suggests that students should begin physics in ninth grade (at 14 years of age), for example, and graduate with an understanding of Newton's laws of dynamics, elasticity, linear systems, electromagnetic mass, the laws of thermodynamics, and quantum behaviour, among other topics.

The group also proposes that students should start chemistry lessons in fifth grade and learn the periodic table and classification of elements, solubility, chemical equilibrium, atomic structure, chemical kinetics and thermochemistry, as well as other topics. In biology, it says, the emphasis should be on genetics and molecular biology.

The group argues that vague approaches to teaching science that fail to challenge students turn them off science and help create an environment where, for example, only 3 per cent of men and 1 per cent of women graduating from US universities have degrees in computer science.

Over the past decade, the number of students graduating in computer science in the United States has dropped by nearly a half, despite burgeoning job opportunities. Scientists must step forward to improve science education and to help lure more financial backing for better teaching laboratories, according to the group.

"(Scientists) are equipped and motivated to insist on teaching fundamentals and basics," says Seaborg, professor of chemistry at the University of California at Berkeley and a former chairman of the Atomic Energy Commission. Seaborg says that science deserves special attention in schools because so much of the job market now requires scientific or technological expertise.

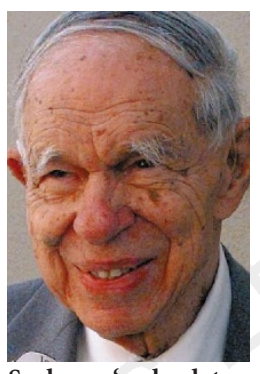

Seaborg: 'go back to basics in teaching'.
"Technology firms are hurting because they can't find people with elementary scientific knowledge," he says; even those in other fields need a basic understanding of science in order to perform adequately as citizens. Seaborg was the lead author of a 1983 report, A Nation at Risk, which detailed educational weaknesses and stimulated a wave of reforms.

The group, which calls itself Associated Scientists, was put together by Shoumen Datta, a molecular biologist who has been active in various education initiatives. Datta says he hopes that curriculum reform in California will stimulate a transformation of teaching methods throughout the country, helping to instil a general standard of excellence in US schools. "We are against the 'process, process' mentality in schools," he says, instead of a focus on accurate content.

Associated Scientists resubmitted its offer to shape academic standards, which it has said it is prepared to do at no cost, shortly before Christmas after a protest had forced the state commission for academic content and standards to rescind the offer of a contract made to another group.

The Institute for Science Education at California State University, San Bernardino, made up primarily of professional educators, had originally won the assignment with a bid costing $\$ 178,000$. One member of the commission's assessment team had explained its decision to award the contract to this group by saying the Nobel laureates "wouldn't know a classroom if you put it in front of them".

Marci McFadden, spokeswoman for the commission, subsequently argued that Associated Scientists had not included sufficient details about the education experience of its members, or the mechanisms by which they planned to accomplish their work. But when the State General Counsel informed the commission it had acted improperly in offering the contract to the San Bernardino institute, the bid process was reopened.

Final proposals were received in the week before Christmas, and the award to the winning contractor is due to be announced by 15 January. It is widely expected that the two teams will collaborate on the project, combining the San Bernardino group's expertise in education techniques with the Nobel laureates' knowledge of science.

SallyLehrman 